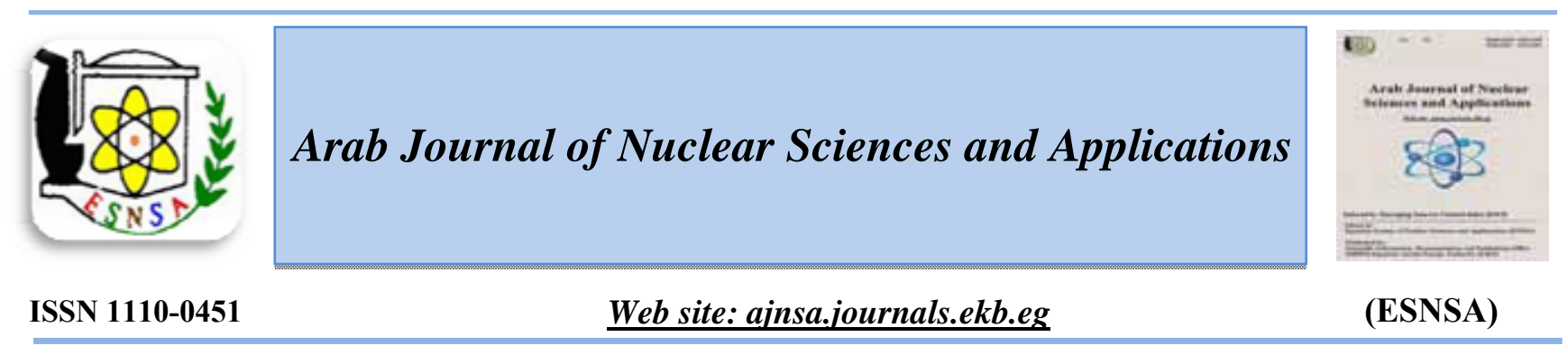

\title{
Natural Radioactivity Levels and the Corresponding Radiation Exposure in Agricultural Environment in Hail, KSA
}

\author{
A. El-Sharkawy ${ }^{(1)}$ and Al-Jawhara Al-Muqren ${ }^{(2)}$ \\ ${ }^{1}$ National Institute of Laser Enhanced Sciences, Cairo University, Giza, Egypt \\ ${ }^{2}$ Physics Department, College of Science, Princess Nora University, Kingdom of Saudi Arabia
}

\begin{abstract}
Received $12^{\text {th }}$ Sep. 2016 The natural radioactivity levels in groundwater, soil and crops have been determined in seven farms at Accepted $14^{\text {st }}$ Nov. 2016 Hail region in Saudi Arabia to assess any radiological hazards to the public, and to maintain a radiological map of natural radioactivity levels in this region. The radium isotopes $\left({ }^{226} \mathrm{Ra}\right.$ and $\left.{ }^{228} \mathrm{Ra}\right)$ were measured in groundwater samples collected from wells in these farms, and the ${ }^{228} \mathrm{Ra}$ activity concentrations exceeded the national guidance level of $2.7 \mathrm{pCi} / \mathrm{L}$ set by Saudi Arabian Standards Organization (SASO) and the WHO. These relatively higher activities did not contribute to the annual effective dose rate from the ingestion of both isotopes $\left({ }^{226} \mathrm{Ra}\right.$ and $\left.{ }^{228} \mathrm{Ra}\right)$ in the analyzed crops, which showed lower values than the upper limit of $1 \mathrm{mSv} / \mathrm{yr}$. The activity concentrations of ${ }^{228} \mathrm{Ra}$ in soils of five farms were found to be higher than the world average value reported by the (United Nations Scientific Committee on the Effects of Atomic Radiation) UNSCEAR. These relatively higher activities contributed to the absorbed dose rate in air from external gamma radiation which was higher than the world average value of $57 \mathrm{nGy} / \mathrm{hr}$ in some farms. These high activities contributed also to the annual effective dose which showed values higher than the world average value of $0.07 \mathrm{mSv} / \mathrm{yr}$ for outdoor terrestrial gamma radiation in three farms. On the basis of these results, it can be concluded that the presence of such activities in the groundwater and crops samples do not pose any radiological hazards or significant risk to the public and animals, since they drink these waters. it may be recommended that the activity levels of the combined radium isotopes in the animal products (milk and meat) and the annual effective dose should be estimated to evaluate the contribution of the ${ }^{228}$ Ra exceeded limits in these wells.
\end{abstract}

Keywords: Radium isotopes, Hail, natural radioactivity, Soil, crops, gamma spectrometry, transfer factor, dose assessment

\section{Introduction}

People are exposed to environmental radiation from many sources. The radioactive contamination of the agricultural environment or a component of it is of a great concern. Radium is present in soil, food, and groundwater. The determination of radium isotopes in the agricultural environment is important in the field of radioprotection since these nuclides partially accumulate in bones, because of the chemical similarity between radium and calcium, leading to rather long residence times in the human body [1]. One of the most important aspects of radioecological studies is to provide the scientific basis for prediction of the impact on man and his environment due to different radionuclides. To assess these impacts quantitatively, it is necessary to estimate the activity concentrations of these isotopes in our environment. Several studies have been carried out to determine the activity concentrations of natural radioactivity in different regions of Saudi Arabia [2-5]. The aim of the present study is to determine the activity concentrations of the combined radium isotopes $\left({ }^{226} \mathrm{Ra}\right.$ and $\left.{ }^{228} \mathrm{Ra}\right)$ in soil samples, irrigation water and crops from seven farms in the Hail region, and

Corresponding author: ahmedtharwat741@gmail.com

DOI: $10.21608 /$ ajnsa.2018.13519

(C) Scientific Information, Documentation and Publishing Office (SIDPO)-EAEA 
to ensure that the radiation exposure and dose received to the public are below the authorized limits, as well as providing a base-line data on natural background radiation in these farms in the Hail region.

\section{Methodology}

\section{Sampling}

The collection of samples was performed at seven farms in the Hail region, as shown in Fig. (1).

For groundwater samples, a five-liter sample was collected from the wells in each farm using a pump. Water was allowed to run in a continuous flow for a short period to eliminate any contamination from the pipes. The sampling containers were rinsed thoroughly with the water to be sampled prior to sample collection. The water samples were filtered through a $0.45 \mu$ membrane filter, acidified with $11 \mathrm{M} \mathrm{HCl}$ at the rate of $10 \mathrm{~mL}$ per liter of sample immediately after filtration to avoid the adsorption of radionuclides on the walls of the container and growth of micro-organisms, and transferred to polyethylene bottles. The soil samples were collected from the cultivated area using a template for guidance to $25 \mathrm{~cm}^{2}$ area and a depth of $15 \mathrm{~cm}$. Three sub-samples were collected at each point and mixed thoroughly to produce a homogeneous representative sample, packed in plastic bags and transferred to the laboratory. The soil samples were oven-dried at $100^{\circ} \mathrm{C}$ to a constant weight, homogenized, sieved through 2 $\mathrm{mm}$ mesh sieve, packed into $100 \mathrm{~mL}$ standard plastic containers and sealed for four weeks to allow secular equilibrium between ${ }^{226} \mathrm{Ra},{ }^{228} \mathrm{Ra}$ and their decay products. The crops samples were collected from the soil sampling points, packed in plastic bags. In the laboratory, they were cleaned from soil particles, weighted, oven-dried at $105^{\circ} \mathrm{c}$, reweighted, packed and sealed in Marinelli-type beakers for analysis.

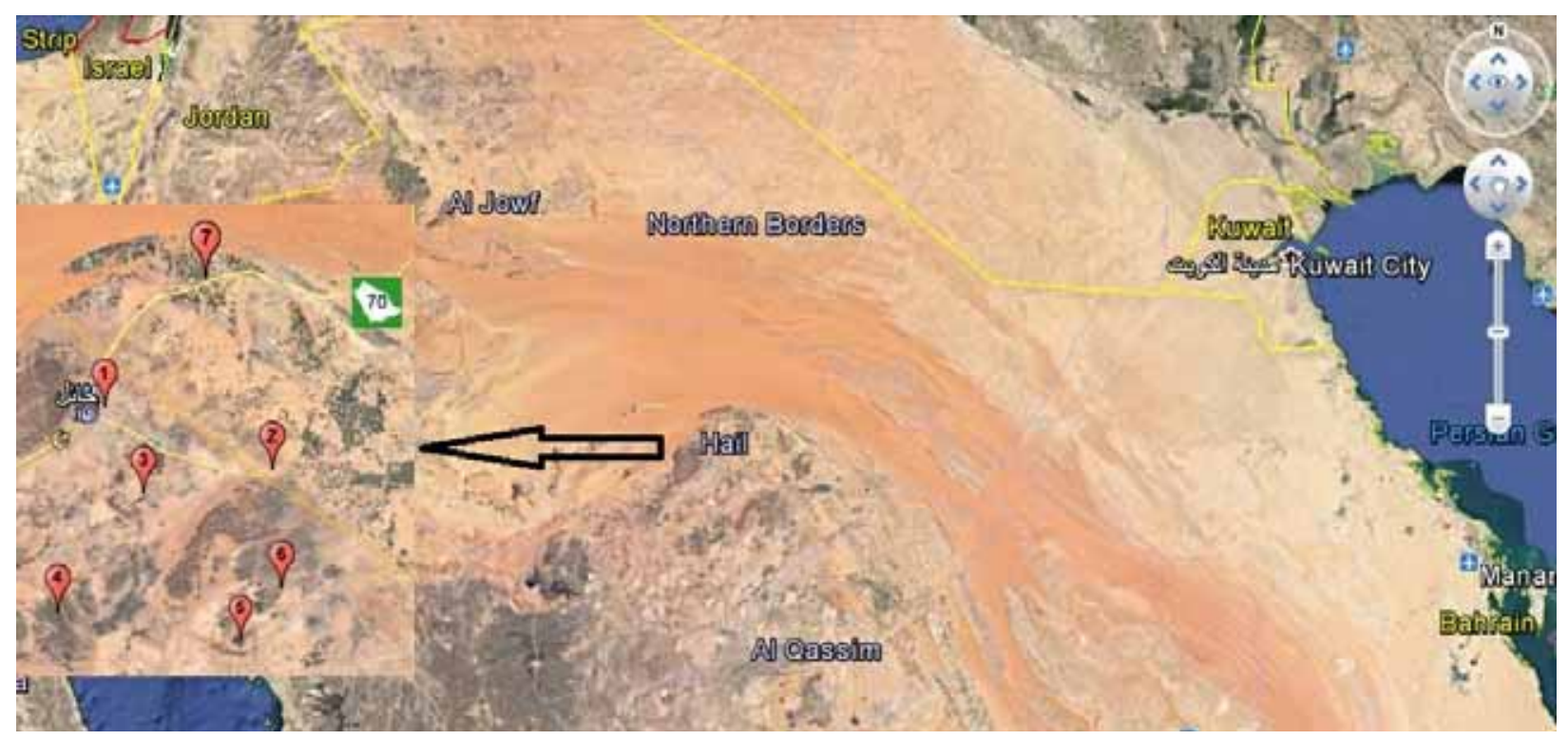

Fig. (1): Saudi Arabia and Location of farms in the Hail Region at the left

\section{Materials and apparatus}

Radium extraction from water samples was carried out using a strong cation exchange resin, Purolite C-100 - Na form, supplied by Veolia Water Co. (Riyadh, Saudi Arabia). Standard reference solutions of ${ }^{226} \mathrm{Ra}$ and ${ }^{228} \mathrm{Ra}$ were supplied by the National Institute of Standards and Technology (NIST), (SRM 4967A, SRM 4339B). The ${ }^{133} \mathrm{Ba}$ standard solution was supplied by North American Technical Services (NATS) (EZ-83879-767). The cation exchange resin was used in a column mode with Bio Rad Glass Econo columns of $0.9 \mathrm{~cm}$ diameter.

\section{Radioanalyses and measurements}

The radium isotopes $\left({ }^{226} \mathrm{Ra}\right.$ and $\left.{ }^{228} \mathrm{Ra}\right)$ were determined in the groundwater samples following the procedure described by A. El-Sharkawy et al, 
2013[6]. Four liters of each sample were allowed to pass through the purolite resin packed columns, the resin was transferred to standard counting containers and the containers were tightly sealed for four weeks to allow secular equilibrium between ${ }^{226} \mathrm{Ra},{ }^{228} \mathrm{Ra}$ and their decay products. The efficiency calibration of the germanium detector for the radium isotopes $\left({ }^{226} \mathrm{Ra}\right.$ and $\left.{ }^{228} \mathrm{Ra}\right)$ was carried out using standard samples. Known activity resins were prepared by spiking water (DDW) samples with known amounts of ${ }^{226} \mathrm{Ra}$ and ${ }^{228} \mathrm{Ra}$ and ${ }^{133} \mathrm{Ba}$ (for chemical recovery). The spiked resin samples containing a known amount of the radionuclide of interest were used to provide an identical matrix with a known activity, and all other conditions were followed typically (flow rate, resin volume, counting time, geometry). The ${ }^{226} \mathrm{Ra}$ activities were determined via its daughters ${ }^{214} \mathrm{~Pb}$ and ${ }^{214} \mathrm{Bi}$ through the gamma energy lines $295.22, \quad 351.93$ and $609.31 \mathrm{keV}$. The ${ }^{228} \mathrm{Ra}$ activities were determined through the gamma energy line of $911.2 \mathrm{keV}$. The calculated specific activities were basically performed using a comparison method:

$$
A_{\text {unk }}=\frac{A_{\text {std }}}{C R_{\text {std }}} \cdot C R_{\text {unk }}
$$

Where:

$\mathrm{A}_{\text {unk }}$ is the calculated activity of the sample; $A_{\text {std }}$ is the activity of the standard resin; $\mathrm{CR}_{\text {std }}$ is the counting rate for the standard resin; and $\mathrm{CR}_{\text {unk }}$ is the counting rate of the unknown sample.

All gamma radioactivity measurements were carried out using a Canberra HPGe coaxial detector with relative photo-peak efficiency of $40 \%$ for the $1332 \mathrm{keV}$ line of ${ }^{60} \mathrm{Co}$. The germanium detector was calibrated using the IAEA-RGU-1 reference material, the absolute efficiency at each specific energy transition of ${ }^{226} \mathrm{Ra}$ was determined, an efficiency curve was fitted and the fitting equation was exploited to calculate the target photopeak efficiencies. The calculations of the activity concentration of ${ }^{226} \mathrm{Ra}$ was based on the gamma energy lines of 295.1, $352.0,609.3 \mathrm{keV}$ and $1764.5 \mathrm{keV}$. For ${ }^{228} \mathrm{Ra}$, the gamma energy line $911.2 \mathrm{keV}$ was used. For ${ }^{40} \mathrm{~K}$, the gamma energy line $1460.8 \mathrm{keV}$ was used. The activity concentration $\mathrm{A}(\mathrm{Bq} / \mathrm{kg})$ at each photopeak was determined using the following equation [20]:
$A=\frac{N e t C R}{F \times \eta_{x} \times M}$

Where $F$ is the intensity per hundred decays for each gamma energy line; $\eta_{\mathrm{x}}$ is the photo peak efficiency and $M$ is the mass of sample $(\mathrm{kg})$. For crops samples, the activities were determined and density corrections were performed, and also for quality assurance purpose, the activity concentrations of the target radioisotopes were calculated by comparison with IAEA plant reference samples of identical matrices in the same conditions (containers, geometry, time).

\section{Quality assurance}

For quality assurance and validation purposes, blank samples were prepared in the same manner as the corresponding samples, and measured for background estimation. Reference water, plant and soil samples (IAEA reference materials and IAEATEL-2014) were determined using the same analysis and measurement protocol, and were compared against their certified values. Errors were propagated due to nuclear counting statistics (ranged from 5 to $8 \%$ ), tracers and volume. The minimum detectable activity (MDA) was calculated according to the equation presented by Currie, 1968 [7].

$$
M D A=\frac{2.71+4.66 \times \sqrt{B G}}{t \times E f f \times V}
$$

\section{Results and Discussion}

\section{Water results}

The activity concentrations of ${ }^{226} \mathrm{Ra}$ and ${ }^{228} \mathrm{Ra}$ in the groundwater samples collected from the seven farms are presented in Fig. (2).

The results of radium levels in the water samples showed that the activity concentrations of ${ }^{226} \mathrm{Ra}$ ranged from 4.0 to $12.7 \mathrm{pCi} / \mathrm{L}$, which are lower than the guideline levels recommended by both, the Saudi Arabian Standards Organization (SASO) and the WHO [8]. For ${ }^{228} \mathrm{Ra}$, the activities ranged from 7.5 to $38.6 \mathrm{pCi} / \mathrm{L}$. All the groundwater samples exceeded the national guidance level of $2.7 \mathrm{pCi} / \mathrm{L}$ for ${ }^{228} \mathrm{Ra}$ set by SASO and the WHO in drinking water. These activity levels may be attributed to the nature of the aquifer rock matrix in this region. The water from these wells is used only for irrigation. These determined activities are lower than those reported in groundwater samples from Jeddah and Tabouk, Saudi Arabia [9].

Arab J. Nucl. Sci. \& Applic. Vol. 51, No.4 (2018) 


\section{Soil results and radiation hazards}

The activity concentrations of ${ }^{226} \mathrm{Ra},{ }^{228} \mathrm{Ra}$ and ${ }^{40} \mathrm{~K}$ in the soil samples collected from the seven farms are shown in table 1 . The values are given in $\mathrm{Bq} / \mathrm{kg}$ on a dry weight basis.

The activity concentrations of ${ }^{226} \mathrm{Ra}$ in the soil samples ranged from 5.4 to $45.3 \mathrm{~Bq} / \mathrm{kg}$, with an average of $28.7 \mathrm{~Bq} / \mathrm{kg}$ and for ${ }^{228} \mathrm{Ra}$, it ranged from 7.2 to $60.1 \mathrm{~Bq} / \mathrm{kg}$, with an average value of 40.8 $\mathrm{Bq} / \mathrm{kg}$, as shown in Fig. (3).

The activities of the combined radium isotopes $\left({ }^{226} \mathrm{Ra}\right.$ and $\left.{ }^{228} \mathrm{Ra}\right)$ showed some variations between the different farms which may be explained by the difference in soil components, texture and the introduction of phosphate fertilizers. All the farms except ( $\mathrm{H} 2$ and $\mathrm{H} 5)$ showed radium activities in soil higher than the world average value as reported by the United Nations Scientific Committee on the Effects of Atomic Radiation (UNSCEAR) [10, 11].

The assessment of the potential exposure of an individual to radioactivity present in the soil samples has been carried out utilizing different indices. The radium equivalent dose (Raeq) was used to estimate the hazards from soils that include ${ }^{226} \mathrm{Ra},{ }^{232} \mathrm{Th}$ and ${ }^{40} \mathrm{~K}$ in $\mathrm{Bq} / \mathrm{Kg}$. This index is defined as:

$\mathrm{Ra}_{\mathrm{eq}}=\mathrm{C}_{\mathrm{Ra}}+1.43 \mathrm{C}_{\mathrm{Th}}+0.077 \mathrm{C}_{\mathrm{K}}$

where : $\mathrm{C}_{\mathrm{Ra}}, \mathrm{C}_{\mathrm{Th}}$ and $\mathrm{C}_{\mathrm{K}}$ are the specific activities of ${ }^{226} \mathrm{Ra},{ }^{232} \mathrm{Th}$ and ${ }^{40} \mathrm{~K}$ in $\mathrm{Bq} / \mathrm{kg}[12,13]$.

Table (1): Natural Radioactivity Levels in the soil samples in $\mathrm{Bq} / \mathbf{k g} \pm 1 \sigma$ uncertainties

\begin{tabular}{lllllll}
\hline $\begin{array}{l}\text { Farm } \\
\text { Code }\end{array}$ & (Ra-226) & $\begin{array}{l}\text { Error } \\
\pm\end{array}$ & Ra-228 & $\begin{array}{l}\text { Error } \\
\pm\end{array}$ & K-40 & Error \pm \\
\hline H1 & 45.3 & 2.3 & 60.1 & 3.0 & 464.4 & 23.2 \\
H2 & 5.4 & 0.3 & 7.2 & 0.4 & 371.0 & 18.5 \\
H3 & 35.1 & 1.8 & 57.3 & 2.8 & 431.8 & 21.6 \\
H4 & 37.6 & 1.9 & 49.5 & 2.5 & 540.2 & 27.0 \\
H5 & 27.9 & 1.4 & 34.6 & 1.7 & 449.0 & 22.5 \\
H6 & 19.4 & 1.0 & 40.0 & 2.0 & 596.5 & 29.8 \\
H7 & 30.0 & 1.5 & 37.2 & 1.9 & 326.9 & 16.3 \\
\hline
\end{tabular}

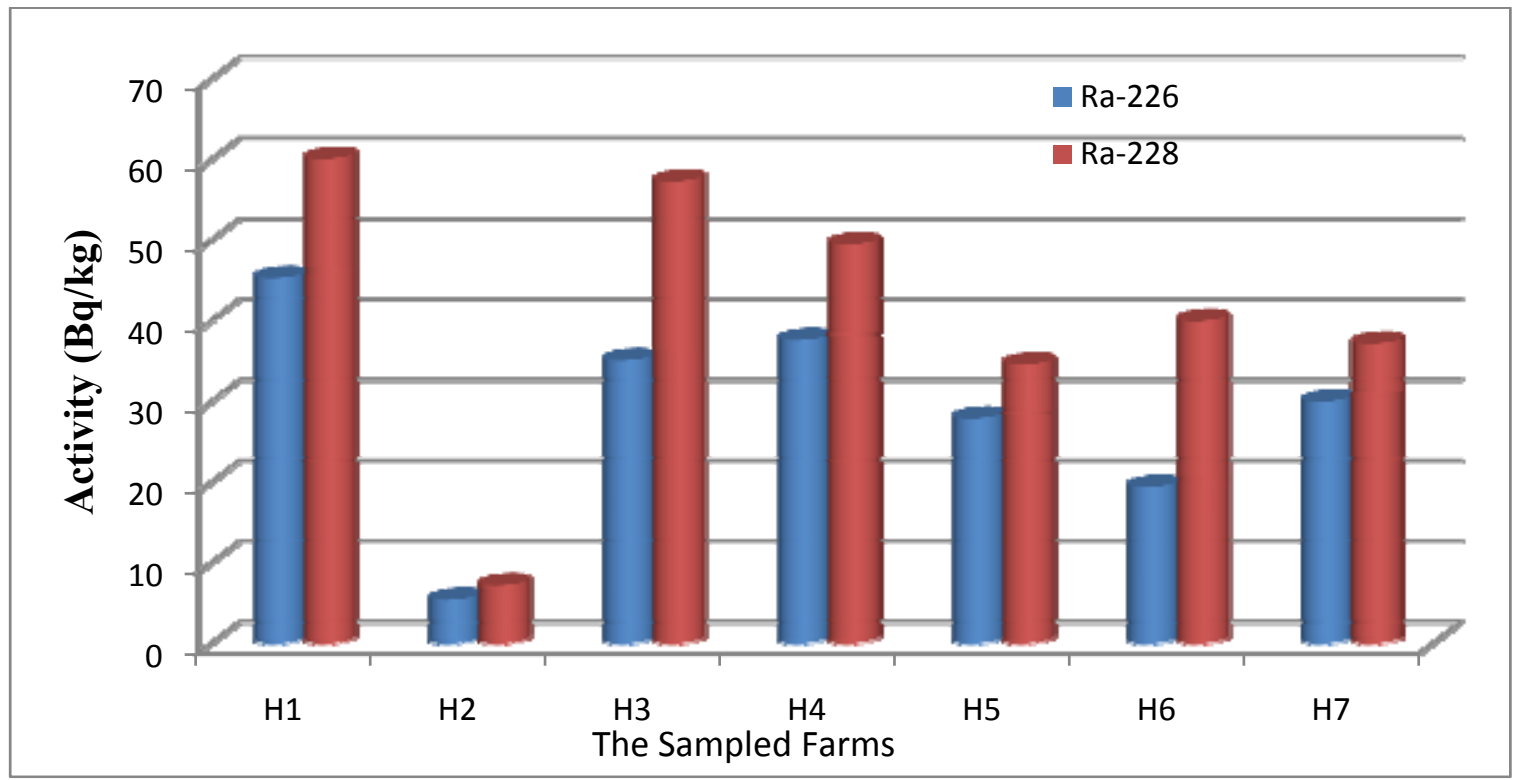

Fig. (3): The activity concentrations of ${ }^{226} \mathrm{Ra}$ and ${ }^{228} \mathrm{Ra}$ in the soil samples 
The radium equivalent activities ranged from 44.3 in farm 2 to $167.0 \mathrm{~Bq} / \mathrm{kg}$ in farm 1 . This value is much lower than the limit of $370 \mathrm{~Bq} / \mathrm{kg}$, as reported by the UNSCEAR. A level of absorbed dose rate in air from the outdoor exposure to gamma radiation in soil was determined at one meter above the ground in $\mathrm{nGy} / \mathrm{hr}$ using the following equation:

$$
\mathrm{D}=\mathrm{R}_{\mathrm{k}} \mathrm{C}_{\mathrm{k}}+\mathrm{R}_{\mathrm{u}} \mathrm{C}_{\mathrm{u}}+\mathrm{R}_{\mathrm{Th}} \mathrm{C}_{\mathrm{Th}}
$$

Where: $\mathrm{D}$ is the absorbed dose in $n G y / h r, R_{k}, R_{u}$, $\mathrm{R}_{\mathrm{Th}}$ are the conversion factors, expressed in $\mathrm{nGy} / \mathrm{hr}$.per $\mathrm{Bq} / \mathrm{kg}(0.46,0.66$ and 0.043 for $\mathrm{K}, \mathrm{U}$ and Th respectively)[10, 14]. The absorbed dose rate ranged from $22.8 \mathrm{nGy} / \mathrm{hr}$ in farm 2 to 80.2 $\mathrm{nGy} / \mathrm{hr}$ in farm 1. In the Survey of Natural Radiation Exposures, the UNSCEAR 2008 refers for asia an average absorbed dose in air outdoors from terrestrial gamma radiation of $57 \mathrm{nGy} / \mathrm{hr}$ [15]. According to this report, the soil samples in four farms ( $\mathrm{H} 1, \mathrm{H} 3, \mathrm{H} 4$ and $\mathrm{H} 6)$ showed an absorbed dose rate higher than the world average value. Based on the absorbed dose rate, a conversion coefficient from absorbed dose to effective dose of 0.7 and an outdoor occupancy factor of $0.2[10,16,17]$, the annual effective dose was calculated using the formula:

$$
\begin{aligned}
& A E D(m S v / y r)=D(n G y / h) \times 8760(h / y r) \times 0.2 \times \\
& 0.7(S v / G y) \times 10^{-6}
\end{aligned}
$$

The annual effective dose was determined from the soils of the seven farms and ranged from 0.03 $\mathrm{mSv} / \mathrm{yr}$ in farm 1 to $0.1 \mathrm{mSv} / \mathrm{yr}$ in farm 2. Farms 1 , 3 and 4 showed values higher than the world average value of $0.07 \mathrm{mSv} / \mathrm{yr}$ for outdoor terrestrial gamma radiation [1], as shown in Table (2).

Some farms in this study showed absorbed dose rates higher than other areas in KSA reported in literature [18], which may be explained by the difference in the soils content of radium isotopes.

\subsection{Radium isotopes in crops and radiation hazards}

Radium isotopes $\left({ }^{226} \mathrm{Ra}\right.$ and $\left.{ }^{228} \mathrm{Ra}\right)$ were measured in the available crops from the seven farms. Based on the determined combined radium activities, the dose coefficients of the relevant radionuclides
${ }^{226} \mathrm{Ra}$ and ${ }^{228} \mathrm{Ra}\left(2.8 \times 10^{-7}\right.$ and $6.9 \times 10^{-7} \quad \mathrm{~Sv} / \mathrm{Bq}$ respectively) and on the estimated annual consumption of these vegetables in Saudi Arabia ${ }^{(1,}$ ${ }^{19)}$, the annual effective dose from the ingestion of radium was determined. Table (3) presents the activity concentrations of ${ }^{226} \mathrm{Ra}$ and ${ }^{228} \mathrm{Ra}$ in the different vegetations on dry weight basis, and the corresponding annual effective dose rate from the ingestion of the combined radium isotopes.

It is shown from Table (3) that the annual effective dose rates from the ingestion of the combined radium isotopes in the analyzed crops are lower than $1.0 \mathrm{mSv} / \mathrm{yr}$, the upper limit recommended for the public by the ICRP [1].

\section{Conclusion and Recommendations}

In this study, Surveillance monitoring in seven farms at the Hail region in Saudi Arabia has been carried out to determine the radioactivity levels of radium isotopes in water and crops, as well as natural radioactivity in soil.

The ${ }^{228} \mathrm{Ra}$ activity concentrations in the groundwater samples exceeded the national guidance level of $2.7 \mathrm{pCi} / \mathrm{L}$ for ${ }^{228} \mathrm{Ra}$ set by Saudi Arabian Standards Organization (SASO) and the World Health Organization for drinking water as a result of the properties of the aquifer rocks in Hail region. The ${ }^{226} \mathrm{Ra}$ and ${ }^{228} \mathrm{Ra}$ were analyzed in the soil and crop samples using gamma ray spectrometry. The activity concentrations of ${ }^{228} \mathrm{Ra}$ in soils of five farms were found to be higher than the world average value reported by the UNSCEAR. These relatively higher activities contributed to the absorbed dose rate in air from external gamma radiation which was higher than the world average value of $57 \mathrm{nGy} / \mathrm{hr}$ in some farms ( $\mathrm{H} 1, \mathrm{H} 3$ and $\mathrm{H} 4)$, and also contributed to the annual effective dose which showed values higher than the world average value of $0.07 \mathrm{mSv} / \mathrm{yr}$ for outdoor terrestrial gamma radiation in three farms. The activity concentrations of the combined ${ }^{226} \mathrm{Ra}$ and ${ }^{228} \mathrm{Ra}$ in the analyzed crop samples ranged from 0.5 to $2.0 \mathrm{~Bq} / \mathrm{kg}$ dry weights respectively. The relatively higher values of ${ }^{228} \mathrm{Ra}$ in the analyzed groundwater samples didn't contribute to the annual effective dose from the ingestion of the combined radium isotopes in crops, which had values lower than $1 \mathrm{mSv} / \mathrm{yr}$ upper limit recommended for the public by the ICRP. On the basis of the current results, it may be concluded 
Table (2): The radium equivalent, the absorbed dose rate and the Annual effective dose from soil samples

\begin{tabular}{cccc}
\hline Farm & $\begin{array}{c}\text { Ra Eq } \\
(\mathrm{Bq} / \mathbf{k g})\end{array}$ & $\begin{array}{c}\text { Absorbed dose rate } \\
(\mathbf{n G y} / \mathbf{h})\end{array}$ & Annual Effective dose (mSv/y) \\
\hline F1 & 167.0 & 80.2 & 0.10 \\
F2 & 44.3 & 22.8 & 0.03 \\
F3 & 150.3 & 72.3 & 0.09 \\
F4 & 150.0 & 72.8 & 0.09 \\
F5 & 112.0 & 54.6 & 0.07 \\
F6 & 122.5 & 60.4 & 0.07 \\
F7 & 108.4 & 52.2 & 0.06 \\
\hline
\end{tabular}

Table (3): The activity concentrations of ${ }^{226} \mathrm{Ra}$ and ${ }^{228} \mathrm{Ra}$ in crops, and the corresponding annual effective dose rates

\begin{tabular}{lllllll}
\hline Farm & Type & $\begin{array}{l}\text { Ra-226 } \\
\text { Bq/kg }\end{array}$ & \pm & $\begin{array}{l}\text { Ra-228 } \\
\mathbf{B q} / \mathbf{k g}\end{array}$ & \pm & $\begin{array}{l}\text { AED } \\
\mathbf{m S v} / \mathbf{y}\end{array}$ \\
\hline F1 & Lettuce & 0.6 & 0.04 & 1.4 & 0.1 & 0.08 \\
F2 & Pepper & 0.1 & 0.01 & 0.4 & 0.1 & 0.02 \\
F3 & Pumpkin & 0.3 & 0.02 & 1.2 & 0.1 & 0.07 \\
F4 & Cabbage & 0.4 & 0.02 & 1.5 & 0.2 & 0.08 \\
F5 & Lettuce & 0.2 & 0.01 & 0.8 & 0.1 & 0.04 \\
F6 & Aubergine & 0.8 & 0.05 & 0.5 & 0.1 & 0.04 \\
F7 & Cabbage & 0.2 & 0.01 & 1.7 & 0.1 & 0.09 \\
\hline
\end{tabular}

that the presence of such activity concentrations of the combined radium isotopes in the groundwater and crops of the investigated farms may not pose any radiological hazards to the public. We may recommend that the activity levels of the combined radium isotopes in the animal products (milk and meat) and the annual effective dose from drinking water should be determined to evaluate the effect of ${ }^{228} \mathrm{Ra}$ exceeded limits in these wells. Also, it would be a good approach to determine the radium activity levels in the leafy vegetables in different seasons. The results of this study could be helpful in radiological mapping of this region and as a baseline data for future studies.

\section{References}

1-International Commission on Radiological Protection ICRP: "Exposure of the population in the united states and Canada from natural background radiation". National Council on Radiation Protection and measurements. Report No.94 (1994).

2-Alkhomashi N, Al-Hamarneh IF, Almasoud FI. "Determination of natural radioactivity in irrigation water of drilled wells in northwestern Saudi Arabia". Chemosphere. Feb;144:1928-36. doi: 10.1016/j.chemosphere.2015.10.094. Epub 2015 Nov 11 (2016).

3-Dheya Al-Othmany. "Natural Radioactivity in Wadi Muhrim, Taif, Saudi Arabia". Journal of Natural Sciences Research, Vol.2, No.10, (2012).
4-Safia H.Q. Hamidalddin. "Determination of agriculture soil primordial radionuclide concentrations in Um Hablayn, north Jeddah west of Saudi Arabia". Int. J. Curr. Microbiol. App. Sci 3(6) 623-633 (2014).

5-ZARIE, K.A. and AL MUGREN, K.S. "Measurements of Natural Radioactivity and Assessment of Radiation Hazard in Soil Samples From TAYMA Area (KSA)". Isotope \& Rad. Res., 42(1), 1-9 (2010).

6-A.El-Sharkawy, Y.Y.Ebaid, W.C.Burnett and S.K.AlDaihan. "A rapid and inexpensive method for ${ }^{226} \mathrm{Ra}$ and ${ }^{228} \mathrm{Ra}$ measurements of high TDS groundwaters". Appl Radiat Isot. Vol.77: 89-93, (2013). 
7-Currie, L.A., "Limits for qualitative detection and quantitative determination". Anal. Chem. 40 (3), 586-593 (1968).

8-WHO Recommendations. "Guidelines for drinking water quality vol. 1". World Health Organization, Geneva (1993).

9-Afaf A. Fakeha, Safiah Q. Hamidalddin, Zain M. Alamoudy, and Ahlam M.A. Al-Amri. "Concentrations of natural radioactivity and their contribution to the absorbed dose from water samples from the Western Province, Saudi Arabia". JKAU: Sci., Vol. 23 No. 2, pp: 17-30 (2011 A.D./1432 A.H.). DOI: 10.4197 / Sci. 23-2.2, (2011).

10-United Nations Scientific Committee on the Effects of Atomic Radiation UNSCEAR.. "Sources and Effects of Ionizing Radiation". Report to the General Assembly, with annexes (2000).

11-G Sankaran Pillai, SM Mazhar Nazeeb Khan, P Shahul Hameed, V Arutchelvan. "Evaluation of radioactivity in soils of Chidambaram taluk of Cuddalore district (Tamil Nadu, India)". International Journal of Applied Research; 1(9): 758-765 (2015).

12-Sroor, A., Afifi, S.Y., Abdel-Haleem, A.S., Salman, A.B., Abdel-Sammad, M., "Environmental pollutant isotope measurements and natural radioactivity assessment for North Tushki area, south Western desert, Egypt". Applied Radiation and Isotopes 57 (3), 427-436 (2002).

13-Ramasamy, V. et al., "Measurement of Natural Radioactivity In Beach Sediments From North East Coast of Tamilnadu, India”. Applied Sciences, Engineering and Technology 1(2): 54-58 (2009).

14-B.G. Bennett, "Exposures to natural radiation worldwide". United Nations Scientific Committee on the Effects of Atomic Radiation (UNSCEAR), Vienna, Austria (1997).

15-United Nations Scientific Committee on the Effects of Atomic Radiation UNSCEAR. Sources and Effects of Ionizing Radiation. Report to the General Assembly, with Scientific annexes. Volume 1 (2008).

16-Papaefthymiou, H. and M. Psichoudaki, "Natural radioactivity measurements in the city of Ptolemais.Journal of Environmental Radioactivity". 99: 1011-1017 (2008).

17-Sam, A.K., Ahamed, M.M.O., Khangi, F.A., E1 Nigumi, Y.O. and Holm, E. "Assessment of terrestrial gamma-radiation in Sudan". Radiation Protection Dosimetry 71(2), 141-145 (1997).

18-Shaikh Abdul Latif, Abdulraheem Abdulrahman Kinsara, Nurul Islam Molla and Mohamed Hamed Nassef. "Natural radioactivity measurements in agricultural soil, fertilizer and crops in some specific areas of Kingdom of Saudi Arabia". Radiochimica Acta. International Journal for chemical aspects of nuclear science and technology, Vol.102, issue 6, (2014).

19-The Suadi Ministry of Agriculture. Per Caput Consumption in the Kingdom of Saudi Arabia. Table
No. (21). (http://www.moa.gov.sa/files/agri/t21.htm) (2002-2004).

20-Q.M.R. Nizam, M.A. Ginnah, M.M. Rahman, M. Kamal, M.I. Chowdhury. "Assessment of Activity Concentrations of Radionuclides from Upper Level Sediment in Charfassion Island, Bhola, Bangladesh". Journal of Nuclear and Particle Physics, 3(3): 36-39 (2013). 